Z Rheumatol $2021 \cdot 80$ (Suppl 2):S76 https://doi.org/10.1007/s00393-021-01121-0

Online publiziert: 8. November 2021

() Der/die Autor(en) 2021

\section{Erratum zu: Apps in der Rheumatologie}

Patrick-Pascal Strunz ${ }^{1}$ Maxime Le Maire ${ }^{2}$ Tobias Heusinger ${ }^{2} \cdot$ Ludwig Hammel $^{3}$. Michael Gernert ${ }^{1}$. Eva C. Schwaneck ${ }^{1,4}$. Johanna Callhoff ${ }^{5,6}$. Jan Portegys ${ }^{1}$.

Marc Schmalzing ${ }^{1} \cdot$ Hans-Peter Tony ${ }^{1} \cdot$ Matthias Froehlich

'Medizinische Klinik II, Abteilung für Rheumatologie und klinische Immunologie, Universitätsklinikum Würzburg, Würzburg, Deutschland

${ }^{2}$ Medizinische Fakultät, Universität Würzburg, Würzburg, Deutschland

${ }^{3}$ Deutsche Vereinigung Morbus Bechterew e. V., Schweinfurt, Deutschland

${ }^{4}$ Asklepios Klinik Altona, Hamburg, Deutschland

${ }^{5}$ Epidemiologie, Deutsches Rheuma-Forschungszentrum Berlin (DRFZ), Berlin, Deutschland

${ }^{6}$ Institut für Sozialmedizin, Epidemiologie und Gesundheitsökonomie, Charité - Universitätsmedizin Berlin, Berlin, Deutschland

\section{Erratum zu:}

\section{Z Rheumatol 2021}

https://doi.org/10.1007/s00393-021-

01104-1

In Tab. 1 zu diesem Artikel waren einige Daten falsch. Der Originalartikel wurde korrigiert.

\section{Korrespondenzadresse}

\section{Dr. med. Patrick-Pascal Strunz}

Medizinische Klinik II, Abteilung für

Rheumatologie und klinische Immunologie, Universitätsklinikum Würzburg

Oberdürrbacher Straße 6, 97080 Würzburg, Deutschland

Strunz_p@ukw.de

Open Access. Dieser Artikel wird unter der Creative Commons Namensnennung 4.0 International Lizenz veröffentlicht, welche die Nutzung, Vervielfältigung, Bearbeitung, Verbreitung und Wiedergabe in jeglichem Medium und Format erlaubt, sofern Sie den/die ursprünglichen Autor(en) und die Quelle ordnungsgemäß nennen, einen Link zur Creative Commons Lizenz beifügen und angeben, ob Änderungen vorgenommen wurden.

Die in diesem Artikel enthaltenen Bilder und sonstiges Drittmaterial unterliegen ebenfalls der genannten Creative Commons Lizenz, sofern sich aus der Abbildungslegende nichts anderes ergibt. Sofern das betreffende Material nicht unter der genannten Creative Commons Lizenz steht und die betreffende Handlung nicht nach gesetzlichen Vorschriften erlaubt ist, ist für die oben aufgeführten Weiterverwendungen des Materials die Einwilligung des jeweiligen Rechteinhabers einzuholen.
Weitere Details zur Lizenz entnehmen Sie bitte der Lizenzinformation auf http://creativecommons.org/ licenses/by/4.0/deed.de.
Die Online-Version des Originalartikels ist unter https://doi.org/10.1007/s00393-021-01104-1 zufinden.

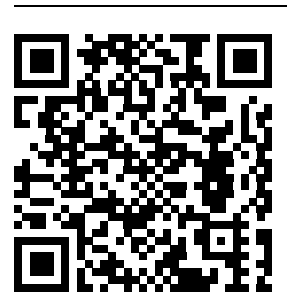

